\title{
ON AFFECTIONS OF SPEECH FROM DISEASE OF THE BRAIN.
}

\author{
BY J. HUGHLINGS-J $\triangle$ OKBON, M.D., F.R.O.P., F.R.8., \\ Phyriotan to the Iondon Hospital, and to the Hoopital for the Epileptio and \\ Paralysed.
}

IT is very difficnlt for many reasons to write on Affections of Speech. So much, sinoe the memorable researches of Dax and Broca, has been done in the investigation of these cases of disease of the brain, that there is an embarras do richesse in material. To refer only to what has been done in this country, we have the names of Gairdner, Moxon, Broadbent, William Ogle, Bastian, John W. Ogle, Thomas Watson, Alexander Robertson, Ireland, Wilks, Bristowe, Ferrier, Bateman, and others. To Wilks, Gairdner, Moxon, Broadbent, and Ferrier, I feel under great obligations. Besides recognising the value of Broadbent's work on this subject, I have to acknowledge a particular indebtedness to him. Broadbent's hypothesis - a verified hypothesis-is, I think, essential to the methodical investigation of affections of speech. Let me give at once an illustration of its value. It disposes of the difficulty there otherwise would be in holding (1) that loss of speech is, on the physical side, loss of nervous arrangements for highly special and complex articulatory movements, and (2) that in cases of loss of speech the articulatory muscles are not paralysed, or but slightly paralysed. I shall assume that the reader is well acquainted with Broadbent's researches on the representation of certain movements of the two sides of the body in each side of the brain; the reader must not assume that Brosdbent endorses the applications I make of his hypothesis. The recent encyclopedic 
article on Affections of Speech, by Kussmaul, in Ziemssen's 'Practice of Medicine,' is very complete and highly original. It is worthy of most careful study.

The subject has so many sides-psychological, anatomical, physiological, and pathological-that it is very difficult to fix on an order of exposition. It will not do to consider affections of speech on but one of these sides. To show how they mutually bear, we must see each distinctly. For example; we must not confound the physiology of a case with its pathology, by using for either the vague term "disease." Again, we must not ignore anatomy when speaking of the physical basis of words, being content with morphology, as in saying that words "reside" in this or that part of the brain. Supposing we could be certain that this or that grouping of cells and nervefibres was concerned in speech, from its being always destroyed when speech is lost, we should still have to find out the anatomy of the centre. Even supposing we were sure that the psychical states called words, and the nerrous states in the "centre for words," were the same things, we should still have the anatomy of that centre to consider. The morphology of a centre deals with its shape, with its "geographical" position, with the sizes and shapes of its constituent elements. A knowledge of the anatomy of a centre is a knowledge of the parts of the body represented in it, and of the ways in which these parts are therein represented. Whilst so much has been learned as to the morphology of the cerebrumcerebral topography-it is chiefly to the recent researches of Hitzig and Ferrier that we are indebted for our knowledge of the anatomy of many of the convolutions, that is, a knowledge of the parts of the body these convolutions represent. It is supposed that the anatomy of the parts of the brain concerned with words is that they are cerebral nervous arrangements representing the articulatory muscles in very special and complex movements. Similarly, a knowledge of the anatomy of the centres concerned during visual ideation is a knowledge of those regions of the brain where certain parts of the organism (retina and ocular muscles) are represented in particular and complex combinations. A merely materialistic or morphological explanation of speech or mind, 
supposing one could be given, is not an anatomical explanation. Morphologically, the substratum of a word or of a syllable is made up of nerve-cells and fibres: anatomically speaking, we say it is made up of nerve-cells and fibres representing some particular articulatory movement.

Unless we most cerefully distinguish betwixt psychology and the anatomy and physiology of the nervous system in this inquiry, we shall not see the fundamental similarity there is betwixt the defect often described in psycholegical phraseology as "loss of memory for words," and the defect called ataxy of articulation. A method which is founded on classifications which are partly anatomical and physiological, and partly psychological, confuses the real issues. These mixed classifications lead to the use of such expressions as that an idea of a word produces an articulatory movement; whereas a psychical state, an "idea of a word" (or simply "a word") cannot produce an articulatory movement, a physical state. On any view whatever as to the relation of mental states and nervous states such expressions are not warrantable in a medical inquiry. We could only say that discharge of the cells and fibres of the anatomical substratum of a word produces the articulatory movement. In all our studies of diseases of the nervous system we must be on our guard against the fallacy that what are physical states in lower centres fine away into psychical states in higher centres; that, for example, vibrations of sensory nerves becoms sensations, or that somehow or another an idea produces a movement.

Keeping them distinct, we must consider now one and now unother of the several sides of our subject: sometimes, for example, we consider the psychical side-speech-and at other times the anatomical besis of speech. We cannot go right on with the prychology, nor with the anatomy, nor with the pathology of our subject. We must consider now one and now the other, endeavouring to trace a correspondence betwixt them.

I do not believe it to be possible for any one to write methodically on these cases of disease of the nervous system without considering them in relation to other kinds of nervous disease; nor to be desirable in a medical writer if it were pos- 
sible. Broadbent's hypothesis is exemplifled in cases of epilepsy and hemiplegia, as well as in cases of affections of speech, and can only be vividly realised when these several diseases have been carefully studied. Speech and Perception ("words" and "images") co-operate so intimately in Mentation (to use Metcalfe-Johnson's term) that the latter process must be considerod. We must speak briefly of Imperception-loss of images-as well as of loss of Speech-loss of symbols. The same general principle is, I think, displayed in each. Both in delirium (partial imperception) and in affections of spech the patient is reduced to a more antomatio condition; respectively reduced to the more organised relations of images and words. Again, we have temporary loss or defect of spech after certain epileptiform seizures: temporary affections of speech after these seizures are of great value in elucidating some difficalt parts of our subject, and cannot be understood without a good knowledge of various other kinds of epileptic and epileptiform paroxysms, and post-paroxysmal states. After a convulsion beginning in the (right) side of the face or tongue, or in both these parts, there often remains temporary speechlessness, although the articulatory muscles move well. Surely we ought to consider cases of discharge of the centres for words as well as cases in which these centres are destroyed, just as we consider not only hemiplegia but hemispasm. Before trying to analyse that very difficalt symptom called ataxy of articulation, we should try to understand the more easily studied disorder of co-ordination, locomotor ataxy ; and before that, the least difficult disorder of co-ordination of movements resulting from ocular paralysis. Unless we do, we shall not successfully combat the notion that there are centres for co-ordination of words which are something over and above centres for special and complex movements of the articulatory muscles, and that a patient can, from lesion of such a centre, have a loss of co-ordination, withont veritable loss of some of the movements represented in it.

It might seem that we could consider cases of aphasia, as a set of symptoms at least, without regard to the pathology of different cases of nervons disease. We really could not. 
It so happens that different morbid processes have what, for brevity, we may metaphorically call different seats of election; thus, that defect of speech with which there are frequent mistakes in words is nearly always produced by local cerebral softening; that defect which is called ataxy of articulation, is, I think, most often produced by hæmorrhage. Hence we must consider hemiplegia in relation to affections of speech; for it so happens that the first kind of defect mostly accurs, as Hammond has pointed ont, without hemiplegia, or without persistent hemiplegia, a state of things producible by embolism and thrombosis, and the latter mostly with hemiplegia and persistent hemiplegia, a state of things usually produced by hæmorrhage. From ignoring such considerations, the two kinds of defects are by some considered to be absolutely different, whereas on the anatomico-physiological side they are but very different degrees of one kind of defect.

There are certain most general principles which apply, not only to affections of speech, but also to the commonest variety of paralysis, to the simplest of convulsive seizures, and to cases of insanity.

The facts that the speechless patient is frequently reduced to the use only of the most general propositions " yes " or " no," or both; that he may be unable to say " no" when told, although. he says it readily in reply to questions requiring dissent; that he may be able ordinarily to put out his tongue well, as for example to catch a stray crumb, and yet unable to put it out when he tries, after being asked to do so; that he loses intellectual Ianguage and not emotional language; that although he does not speak, he understands what we say to him; and many other facts of the same order, illustrate exactly the same principle as do such facts from other cases of disease of the nerrous system as-that in hemiplegia the arm suffers more than the leg; that most convulsions beginning unilaterally begin in the index finger and thumb; that in cases of post-epileptic insanity there are degrees of temporary reduction from the least towards the most "organised actions," degrees proportional to the severity of the discharge in the paroxysm, or rather to the amount of exhaustion of the highest centres produced by the discharge causing the paroxysm. In all 
these cases-except in the instance of convulsion, which, however, illustrates the principle in another way-there are, negatively, degrees of loss of the most voluntary processes with, positively, conservation of the next most voluntary or next more automatic; otherwise put, there are degrees of loss of the latest acquirements with conservation of the earlier, especially of the inherited, acquirements ; speaking of the physical side, there are degrees of loss of function of the least organised nervous arrangements with conservation of function of the more organised. There is in each reduction to a more automatio condition: in each there is Dissolution, using this term as Spencer does, as the opposite of Evolution.'

In defects of speech we may find that the patient utters instead of the word intended a word of the same class in meaning, as "worm-powder" for " cough-medicine"; or, in sound, as "parasol" for "castor oil." The presumption is that the patient uses what is to him a more "organised " or "earlier" word, and if so, Dissolution is again seen. But often there is no obvions relation of any sort betwixt the word said and the one appropriate, and thus the mistake does not appear to come under Dissolution. If, however, we apply the broad principles which we can, I think, establish from other cases of Dissolution, viz. from degrees of insanity-especially the slight degrees of the post-epileptic insanity just spoken of-we shall be able to show that many of the apparently random mistakes in words are not real exceptions to the principle of Dissalution.

For the above reasons I shall make frequent references to other classes of nervous disense. The subject is already complex without these excursions, but we must face the complexity. Dr. Curnow has well said (Medical Times and Gazette, Nov. 29, p. 616), "The tendency to appear exact by disregarding the complexity of the factors is the old failing in our medicel history."

1 Here I mast acknowledge my great indebtedness to Spencer. The fhots stated in the tert conclusions he lias arrived at deductively in his Prycholagy. It is not attirmed that we have the exact opposite of Evolution from the apparently brutal doinga of disease: the proper opposite is seon in healthy senescense, as Bpencer has shown. But from disease there is, in general, the corresponding opposite of Evolution. 
Certain provisional divisions of our subject must be made. The reader is asked to bear in mind that these are admittedly arbitrary; they are not put forward as scientific distinctions. Divisions ${ }^{1}$ and Arrangements are ensy, Distinctions and Classifications are difficult. But in the study of a very complex matter, we must first divide, and then distinguish. This is not contradictory to what was said before on the neccssity of encountering the full complexity of our subject. Harm comes, not from dividing and arranging, but from stopping in this stage, from taking provisional divisions to be real distinctions, and putting forward elaborate arrangements, with divisions and subdivisions, as being classifications. In other words, we shall, to start with, consider our subject empirically, and afterwards scientifically; we first arbitrarily divide and arrange for convenience of obtaining the main facts which partirular cases supply, and then try to classify the facts, in order to show their true relations one to another, and consider them on the psychical side as defects of mind, and on the physical side as defects of the nervous system. Empirically we consider the cases of affection of speech we meet with, as they approach certain nosological types (most frequently occurring crses), scientifically we classify the facts thus obtained, to show how affections of speech are departures from what we know of healthy states of mind and body. The latter stady is of the cases as they show different degrees of nervous Dissolation.

Let us first of all make a very rongh popular division. When a person "Talks" there are three things going onSpeoch, Articulation, and Voice. Disease can separate them. Thus from disease of the larynx, or from paralysis of its

1 "How often would controversies be eweetened were peoplo to remember that 'Dirtinotions and Divisions are very difforent things,' and that 'one of them is the most neceseary and conducive to true knowledge that can be: the other, when mado too much of, erree only to paxsle and confuse the undenetending.' Looke's words are the germ of that wise ephorism of Coleridge: 'It is a dull or obtuse mind that must divide in order to distinguish; but it is a still worse thet dietingainhes in order to divide.' And if wo cast our eyes back over time, it in the same opirit as that which led Anaragoras to say, "Things in this one connected world are not cut off from one another as if with a hatchet." "- Weatrainuter Roviow (art. Locke), January 1877 (no italics in original). 
nerves, we have loss of voice, but articulation and speech remain good. Again, in complete paralysis of the tongue, lips, and palate, articulation is lost, but speech is not even impaired; the patient remains able to express himself in writing, which shows that he retains speech-internal speech -that he propositionises well. Laatly, in extensive disease in a certain region in one half of the brain (left half usually) there is loss of spech, intermal and external, but the articulatory muscles move well.

Let us make a wider division. Using the term Language, we make two divisions of it, Intellectual and Emotional. The patient, whom we call speechless (he is also defective in pantomime), has lost intellectual language and has not lost emotional language.

The kind of case we shall consider first is that of a man who has lost speech, and whose pantomime is impaired, but whose articulatory muscles move well, whose vocal organs are sound, and whose emotional manifestations are unaffected. This is the kind of case to be spoken of as No. 2 (p. 314).

The term Aphasia has been given to affections of apeech by Troussean ; it is used for defects as well as for loss of speech. I think the expression Affections of Speech (including defects and loss) is preferable. Neither term is very good, for there is, at least in many cases, more than loss of speech ; pantomime is impaired; there is often a loss or defect in symbolising relations of things in any way. Dr. Hamilton proposes the term Asemasia, which seems a good one. He derives it " from $a$ and onpaivo, an inability to indicate by signs o. language." It is too late, I fear, to displace the word aphasia. Aphasia will be sometimes nsed as synonymous with $\Lambda$ ffections of Speech in this article.

We mast at once say briefly what we mean by spoech, in addition to what has been agid by implication when excluding articulation, as this is popularly understood, and voice. To speak is not simply to utter words, it is to propositionise. A proposition is such a relation of words that it makes one new meaning; not by a mere addition of what we call the separate meanings of the several words; the terms in a proposition are 
modified ${ }^{I}$ by each other. Single words are meaningless, and so is any unrelated succession of vords. The unit of speech is a proposition. A single word is, or is in effect, a proposition, if other words in relation are implied. The English tourist at a French table d'hote was understood by the waiter to be asking for water when his neighbours thought he was crying "ohl" from distress. It is from the use of a word that we judge of its propositional value. The words "yes" and "no" are propositions, but only when used for assent and dissent; they are used by healthy people interjectionally as well as propositionally. A speechless patient may retain the word "no," and yet have only the interjectional or emotional, not the propositional, use of it; he utters it in various tones as signs of feeling only. He may have a propositional use of it, but yet a use of it short of that healthy people have, being able to reply "no," but not to say "no" when told; a speechless patient may have the full use of it. On the other hand, elaborate oaths, in spite of their propositional structure, are not propositions, for they have not, either in the mind of the utterer or in that of the person to whom they are uttered, any meaning at all; they may be called "dead propositions." The speechless patient may occasionelly swear. Indeed he may have a recurring utterance, e.g. "Come on to me," which is propositional in structure but not, to him, propositional in use; he utters it on any occasion, or rather on no occasion, but every time he tries to speak.

Loss of speech is therefore the loss of power to propositionise. It is not only loss of power to propositionise aloud (to talk), but to propositionise either internally or externally, and it may exist when the patient remains able to utter some few words. We do not mean, by using the popular term power, that the speechless man has lost any "facnlty" of speech or propositionising; he has lost those words which serve in speech, the nervous arrangements for them being destroyed. There is no "faculty" or "power" of speech apart from words revived or revivable in propositions, any more than there is a "faculty" of co-ordination of move-

' On this matter see an able arlicle in the Cornhull Magatine, May 1866. See also Waitz, 'Anthropology' (Collingwood's Translation), p. 241 et eeq. 
ments apart from movements represented in particular ways: We must here say too that besides the use of words in speech there is a service of words which is not speech; hence we do not use the expression that the speechless man has lost words, but that he has lost those words which serve in spech. In brief, Spechlessness does not mean entire Wordlessness.

It is well to insist again that speech and words are psychical terms; words have of course anatomical substrata or bases as all other psychical states have. We must as carefully distinguish betwixt words and their physical bases, as we do betwixt colour and its physical basis; a psychical state is always accompanied by a physical state, but nevertheless the two things have distinct natures. Hence we must not say that the "memory of words" is a funotion of any part of the nervous system, for function is a physiological term (vide infrà). Memory or any other psychical state arises during not from-if "from" implies continuity of a psychical state with a physical stato-functioning of nerrous arrangoments, which functioning is a purely physical thing-a discharge of nervous elements representing some impressions and movements. Hence it is not to be inferred from the rough division we just made of the elements of "talking," and from what was said of their "separation" by disease, that there is anything in common even for reasonable contrast, much less for comparison, betwixt loss of speech (a psychical loss) and immobility of the articulatory muscles from, say disease of the medulla oblongata, as in " bulbar paralysis" (a physical loss). As before said, we must not classify on a mixed method of anatomy, physiology, and psychology," any more than we should classify plants on a mixed natural and empirical method, as exogens, kitchen-herbs, graminacem, and shrubs. The things comparable and contrastable in the rough division are (1) the two physical losses: (a) loss of function of certain nervous arrangements in the cerebrum, which are not spech (Fords used in speech), but the anatomical substrata of speech; and (b) loss of function of nervous arrangements in the medulla oblongata. (2) The comparison, on the psychical side, fails. There is no psychical loss in disense of the medulla 
oblongata to compare with loss of words, as this part of the nervous system, at lesst as most suppose, ${ }^{1}$ has no psychical side; there is nothing psychical to be lost when nerrous arrangements in the medulla oblongata are destroyed.

- The affections of speech met with are very different in degree and kind, for the simple reason that the exact position of disease in the brain and its gravity differ in different cases; different amounts of nervous arrangements in different positions are destroyed with different rapidity in different persons. There is, then, no single well-defined "entity"loss of apeech or aphasia-and thus, to state the matter for a particular practical purpose, such a question as, "Can an aphasic make a will?" cannot be answered any more than the question, "Will a piece of string reach across this room?" can be answered. The question should be, "Cen this or that aphasic person make a will?" Indeod, we have to consider degrees of affection of Language, of which speech is but a part. Admitting the occurrence of numerous degrees of affection of Language, we must make arbitrary divisions for the first part of our inquiry, which is an empirical one.

Let us divide roughly into three degrees: (1) Defect of Spech.-The patient has a full vocabulary, but makes mistakes in words, as saying "orange" for "onion," "chair" for "table"; or he uses approximative or quasi-metaphorical expressions, as "Light the fire up there," for "Light the gas." "When the warm water comes the weather will go away," for "When the sun comes out the fog will go away." (2) Loss of Spoech.-The patient is practically spoechless and his pantomime is impaired. (3) Lass of Language.Besides being spechless, he has altogether lost pantomime, and emotionel language is deeply involved.

To start with, we take the simplest case, one of loss of spech, No. 2 ("complete aphasia"). Cases of defect of speech (1) are far too difficult to begin with, and so, too, are those ceses (3) in which there is not only loss of speech,

I I, however, believe, as Lewee does, that in so far as we are phyically alivo, we are prychically alive; that some peychical state attende every condition of notivity of every part of the organiam. This ia at any rate, a convenient hspothesis in the study of diseseas of tho nerrons syotem. 
but also deep involvement of that least special part of language which we call emotional language. Moreover, we shall deal with a case of permanent speechlessness. I admit that making but three degrees of affection of language, and taking for consideration one kind of frequently occurring case, is an entirely arbitrary proceeding, since there actually occur very numerons degrees of affection of language, many slighter than, and some severer than, that degree (No. 2) we here call one of loss of spech. But, as aforesaid, we must study subjects so complex as this empirically before we study them scientifically; and for the former kind of study we must have what are called "definitions" by type, and state exceptions. This is the plan adopted in every work on the practice of medicine with regard to all diseases. Let us give an example of the twofold study. Empirically or clinically, that is for the art of medicine, we should consider particular cases of epilepsy as each approaches this or that nosological type ("le petit mal, le grand mal," \&c.). For the science of medicine we should, so far as is possible, consider cases of epilepsy as each is dependent on a "discharging lesion" of this or that part of the cortex cerebri, and thus as it is a departure from healthy states of this or that part of the organism. We cannot do the latter fully yet, but the anatomico-physiological researches of Hitzig and Ferrier have marvellously helped us in this way of stadying epilepsies, as also have the clinical researches of Broadbent, Charcot, Duret, Carville, and others. ${ }^{1}$

The following are brief and dogmatic statements about a condition which is a common one-the kind of one we call loss of speech, our second degree (No. 2) of Affection of

1 Seo Moron, On the Necessity for a Clinical Nomenclatare of Disense, Guy's Hospital Reports, vol. I7. In this paper Moxon showg conclusively the necesaity of keoping tho clinical, or what is abovo called empirical-not asing that term in its popular bad signification-and soientifio studies of disanse distinct. After reading this paper, my eyes were opened to the confusion which results from mixing the two kinds of atudy. It is partioularly important to have both an empirical arrangement and a ecientific clnesiflcation of creses of Insanity. An example of the former is the nuch-ariticised arrangoment of 8kae; the scientiflo classiffcation of cases of insunity, like that of affections of speech, would be regarding them as instances of Dissolution: the Dissolution in ineanity begina in the highost and most complex of all corcbral norvous arrangements, the Dissolution 
Language. The statements are about two equally important things; (1) of what the patient hes lost in Language-his negative condition, and (2) of what he retains of Languagehis positive condition. Here, again, is an illustration of a general principle which is exemplified in many if not in all cases of nervous disease, and one of extreme importance when they are scientiffcally considered as instances of nerrous Dissolution. We have already stated the duality of many symptomatic conditions in the remarks on p. 308. Without recognising the two elements in all cases of affections of speoch, we shall not be able to classify affections of speech methodically. If we do not recognise the duplex (negative and positive) condition, we cannot possibly trace a relation betwixt Nos. 1, 2 , and 3 (p. 314). There can be no basis for comparison betwixt the wrong utterances in No. 1 and the non-atterances in Nos. 2 and 3-betwixt a positive and a negative condition-betwixt spech, however bad, and no speech. There is a negative and a positive condition in exch degree; the comparison is of the three degrees of the negative element and the three degrees of the positive element; the negative and positive elements vary inversely. The condition of the patient No. 1, who made such mistakes as saying "chair" for "table" was duplex; (a) negatively in not saying "table," and (b) positively, in saying "chair" instead; there is in such a case loss of some speech, with retention of the rest of speech. Hence the term defect of speech applied to such a case is equivocal; it is often used as if the actual ntterance was the direct result of the disease. The utterance is wrong in that the words of it do not fit the things intended to be indicated; but it is the best speech under the circunstances, and is owing to activity of healthy (except perhaps slightly unstable) nervous elements. The real, the primary, fanlt is in the nervous elements which do not act, which are destroyed, or are for the time hors de combat. If then we compare No 1 with No. 2, we

causing affections of speech in a lower series. The one kind of classiflation is fur diagnosis (for direct "practical purposes"), the other is for increase of knowledge, and is worthless for immediato practical purposes. The fault of somo alıseifleations of insanity is that they are mixed, partly enpirical nnd partly coiontifle. 
compare the two negative conditions, the inability to eay "table," \&c. (the loss of some speech) in No. 1, with the loss of nearly all speech in No. 2, saying the latter is a greater degree of the former, and we compare the two positive conditions, the retention of inferior speech (the wrong utterances) in No. 1, with in No. 2 the retention of certain recurring atterances and with the retention of emotional language, saying the latter is a minor or lower degree of language than the former. Unless we take note of the duplex condition in imperception (delirium and ordinary insanity), we shall not be able to trace a correspondence betwixt it and other nervous diseases. There are necessarily the two opposite conditions in all degrees of mental affections, from the slightest "confusion of thought" to dementia, unless the dementia be total.

\section{The Patient's Negative Condition.}

(1) He does not speak.-He can, the rule is, atter some jargon, or some word, or some phrase. With rare exceptions, the utterance continues the same in the same patient : we call these Recurring Utterances. The exceptions to the statement that he is speechless are two. (a) The recurring utterance may be "yes," or "no," or both. These words are propositions when used for assent or dissent, and they are so used by some patients who are for the rest entirely speechless. (b) There are Occasional Utterances. Under excitement the patient may swear: this is not speech, and is not exceptional; the oath means nothing ; the patient cannot repeat it, he cannot "say" what he has just "uttered." Sometimes, however, a patient, ordinarily speechless, may get out a phrase appropriate to some simple circumstance, such as "good-bye" when a friend is leaving. This is an exception, but yet only a partial excep-

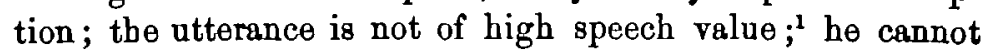

1 What is meant by an uttoranou of high epeech value and by inferior epeoch will later on be atated more folly than has been just now atated by implication. When we cease dealing with our subject empirically and treat it scientifloally, wo hope to show that thes so-called exceptions come in place under the principle of Diseolution. We min now say that spech of high value, or superior speoch, is new epeoch, not necessarily, new words and possibly not new combinations of words; propositions symbolising relations of image now th the epeaker, as in carofully describing something novel. It is tho latest propositionising. By inferior 
"say" it again, cannot repeat it when entreated; it is inferior speech, little higher in value than swearing. However, sometimes a patient, ordinarily speechless, may get out an utterance of high speech value; this is very rare indeed.

(2) $H_{\theta}$ cannot write; that is to say, he cannot express himself in writing. This is called Agraphia (William Ogle). It is, I think, only evidence of the loss of apeech, and might have been mentioned in the last paragraph. Written words are symbols of symbols. Since he cunnot write, we see that the patient is speechless, not only in the popular sense of being nnable to talk, but altogether so; he cannot speak internally. There is no fundamental difference betwixt external and internal speech; each is propositionising. If I say "gold is yellow" to myself, or think it, the proposition is the same; the same symbols referring to the same images in the same relation as when I say it alond. There is a difference, but it is one of degree; psychically "faint" and "vivid," physically "slight" and "strong" nervous discharges. The spechless patient does not write because he has no propositions to write. The speechless man may write in the sense of penmanship; in most cases he can copy writing, and can usaally copy print into writing, and very frequently he can sign his name without copy. Moreover he may write in a fashion without copy, making, or we may say drawing, a meaningless succession of letters, very often significantly the simplest letters, pothooks. His handwriting may be a very bad scrawl, for he may have to write with his left hand. His inability to write, in the sense of expressing himself, is loss of spech; his ability to make ("to draw") letters, as in copying, \&c., shows that his "image series" (the materials of his perception) is not damaged.

Theoretically there is no reason why he should not write music without copy, supposing of course that he could have done that when well; the marks (artificial images) used in noting music, have no relation to words any way used. On this matter I have no observations. Trousseau writes in his

meoch is meant utterances like, "Very well," "I don't think so," ready fltted to very gimple and common circumetunoces, the nervons arrangemonte for them boing woll organised. 
Lecture on Aphasia (Syd. Sac. Trans. vol. i. p. 270), "Dr. Lasegue knew a musician who was completely aphasic, and who could neither read nor write, and yet could note down a musical phrase sung in his presence."

(3) In most cases the speechless patient cannot read at all, obviously not aloud, but not to himself either, including what he has himself copied. We suppose our patient cannot read. This is not from lack of sight, nor is it from want of perception; his perception is not itself in fault, as we shall see shortly.

(4) His power of making signs is impaired (pantomimic propositionising). We must most carefully distinguish pantomime from gesticulation. Throwing up the arms to signify " higher up," pantomime, differs from throwing up the arms when surprised, gesticulation, as a proposition does from an oath.

So far we have, I think, only got two things, loss of speech (by simple direct evidence, and by the indirect evidence of . non-writing and non-reading) and defect of pantomime. There are in some cases of loss of speech other inabilities; the most significant are that a patient cannot put out his tongue when he tries, or execute other movements he is told, when he can move the parts concerned in other ways quite well.

\section{The Patient's Positive Condition.}

(1) He can understand what.we say or read to him; he remembers tales read to him. This is important, for it proves that, although Speechless, the patient is not Wordless. The hypothesis is that words are in duplicate; and that the nervous arrangements for words used in speech lie chiefly in the left half of the brain; that the nervous arrangements for words used in understanding speech (and in other ways) li $\theta$ in the right also. Hence our reason for having used such expressions as "words serving in speech ;" for there is, we now see, another way in which they serve. When from disense in the left balf of the brain speech is lost altogether, the patient understands all we say to him, at least on matterg simple to him. Further it is supposed that another use of the words which re- 
main is the chief part of that service of words which in health precedes speech; there being an unconscious or subconscious revival of words in relation before that second revival which is speech. Coining a word, we may say that the process of Verbalising is dual; the second "half" of it being speech. It is supposed also that there is an anconscious or subconscious revival of relations of images, before that revival of images in relation which is Perception:

(2) His articulatory organs move apparently well in eating, drinking, swallowing, and also in such utterances as remain always possible to him (recurring utterances), or in those which come out occasionally. Hence his speechlessness is not owing to disease of those centres in the medulla oblongata for immediately moving the articulatory musoles; for in other cases of nervous disease, when these centres are so damaged that the articulatory muscles are so much paralysed that talking is impossible, the patient remains able to speak (to propositionise) as well as ever; he has internal speoch, and can write what he speaks.

The following dicta may be of use to beginners. Using the popular expression " talk," we may say that if a patient does not talk because his brain is diseased, he cannot write (express himself in writing), and can swallow well; if he cannot talk because his tongue, lips, and palate are immovable, he can write well and cannot swallow well.

(3) His rocal organs act apparently well; he may be able to sing.

(4) His emotional language is apparently unaffected. He smiles, langhs, frowns, and varies his voice properly. His recurring atterance comes out now in one tone and now in another, according as he is vexed, glad, \&c. ; strictly we should say he sings his recurring utterance; variations of voice being rudimentary song (Spencer); he may be able to sing in the ordinary meaning of that term. As stated already, he may swear when excited, or get out more innocent interjections, simple or compound (acquired parts of emotional language). Although he may be unable to make any but the simplest signs, he gesticulates apparently as well as ever, and probably be does so more frequently and more copiously than he 
used to do. His gesticulation draws attention ta his needing something, and his friends guess what it is. His friends often erroneously report their guessing what he wants when his emotional manifestations show that he is needing something, as his expressing what thing it is that he wants.

So far for the negative and positive conditions of Language in our type case of Loss of Speech-No. 2 in Defect of Language.

Words are in themselves meaningless, they are only symbols of things or of "images" of things; they may be said to have meaning "behind them." A proposition symbolises a particular relation of some images."

We must then briefly consider the patient's condition in regard to the images symbolised by words. For although we artificially separate speech and perception, words and images co-operate intimately in most mentation. Moreover, there is a morbid condition in the image series (Imperception), which corresponds to aphasia in the word series. The two should be studied in relation.

The spechless patient's perception (or "recognition," or "thinking" of things) (propositions of images) is unaffected, at any rate as regards simple matters. To give examples : he will point to any object he knew before his illness which we name; he recognises drawings of all objects which he knew before his illness. He continues able to play at cards or dominoes; he recognises handwriting, although he cannot read the words written; he knows poetry from prose, by the different endings of the lines on the right side of the page. One of $\mathrm{my}$ patients found out the continuation of a series of papers in a magazine volnme, and had the right page ready for her husband when he returned from his work; yet she, since her ill-

1The term "image" is ased in a peychical sense, as the term " word" fs. It does not mean "visual "'images only, but covers all mental states which represent thiuge. Thas we speak of auditory images. I believe this is the way in which Taine usca the term image. What is hero onlled "an image" is sometimes spoken of as "a perception." In this article the term perception is used for a procese, for a "proposition of images," as apeech is used for propositions, i.e. partloulur inter-relutions of words. The expresaion "organised image" is used briefly for "image, the norvous arrangemonts for tohich are organised," correspondingly for "organized word," \&c. 
ness, could not read a word herself, nor point to a letter, nor could she point to a figure on the clock. There is better and simpler evidence than that just adduced that the image series is unaffected; the foregoing is intended to show that the inability to read is not due to loss of perception nor to nonrecognition of letters, \&c., as particular marks or drawings: but to loss of speech. Written or printed words cense to be symbols of words used in speech for the simple resson that those words no longer exist to be symbolised; the written or printed words are left as symbols of nothing, as mere odd drawings. The simplest example showing the image series to be undamaged is that the patient finds his way about; this requires preconception, that is "propositions of images " of streets, \&c. Moreover, the patient can, if he retains the propositional use of "yes" and "no," or if he has the equivalent pantomimic symbols, intelligently assent or dissent to simple statements, as that "Racehorses are the swiftest horses," showing that he retains organised nervous arrangements for the images of the things "swiftness" and "horse"; this has already been implied when it was asserted that he understands what we say to him, a process requiring not some of his words only, but also some of his "images" of things, of which the words are but symbols.

Such facts as the above are sometimes addaced as showing that the patient's "memory" is unaffected. That expression is misleading, if it implies that there is a general faculty of memory. There is no faculty of memory apart from things being remembered; apart from having, that is, now and again, these or those words, or images, or actions (faintly or vividly). We may say he has not lost the-memory of images, or, better, that he has the images actually or potentially ; the nervous arrangements being intact and capable of excitation did stimuli come to them; we may say that he has lost the memory of those words which serve in speech. It is better, however, to use the simple expression that he has not lost images, and that he has lost the words used in speech.

These facts as to retention of images are important as regards the writing of spechless patients. The printed or written letters and words are images, but they differ from 
the images of objects, in being artificial and arbitrary, in being acquired later; they are acquired after speech and have their meaning only through speech; written words are symbols of symbols of images. The aphasic patient cannot express himself in writing because he cannot speak; but the nerrous arrangements for those arbitrary images which are named letters are intact, and thas he can reproduce them as mere drawings, as he can other images, although with more difficulty, they, besides lacking their accustomed stimulus, being less organised. He can copy writing, and he can copy print into writing. When he copies print into writing, obviously he derives the images of letters from his own mind (physically his own organisation). He does not write in the sense of expressing himself, becanse there are no words reproduced in speech to express. That series of artificial images which makes up the signature of one's name has become almost as fully organised as many ordinary images; hence in many cases the speechless man who can write nothing else without copy can sign his name.

For the perception (or recognition or thinking) of things, at least in simple relations: speech is not necessary, for such thought remains to the spechless man. Words are required for thinking, for most of our thinking at least, but the spechless man is not wordless; there is an automatic and unconscions ${ }^{1}$ or subconscions service of words.

It is not of course said that speech is not required for thinking on novel and complex subjects, for ordering images in new and complex relations (i.e. to the person concerned),

1 The expression "unconscious reproduction of words" involves the same contradiotion as does the expression, "unconscious sensation." Such expressions may be taken to mean that energising of lower, more organised, nerrous arrangements, although unattended by any sort of conscions state, is essential for, and leads to, partioular energinings of the highest and least organised-the noworganising-nerrous arrangements, which last-mentioned enargising is attended by conscionsness. I, however, think (as Lewes does) that some consciousnese or "sensibility" attonds energising of all nervous arrangements (I wee the term subconecious for alight consolousuess). In cases where from disease the highert nervous arrangements are suddenly placed hors do combat, as in eudden delirium, the next lower opring into greater activity; and then, what in health was a subordinate suboonscioumess, becomes a vivid conscionsmess, and is also the highest coneciuueness thure then can be. 
and thus the process of perception in the speechless, but not wordless, man may be defective in the sense of being inferior from lack of co-operation of speech : it is not itself in fault, it is left unaided.

To understand anything novel and complex said to him, the healthy man speaks it to himself, e.g. reperts, often aloud, complex directions of route given to him.

The word "thing" has not bean used as merely synonymous with "substance"; nor is it meant that anybody has nerrous arrangements for the images of "swiftness" and "horse," but only for images of some swiftly-moving thing or things, and for images of some particular horse or horses.

It may be well here to give a brief recapitulation of some parts of our subject and, also very briefly, an anticipation of what is to come; the latter is given partly as an excuse for having dwelt in the foregoing on some points not commonly considered in such an inquiry as this, and partly to render clearer some matters which were only incidentally referred to.

The division into internal and external speech (see p. 318) is not that just made into the dual service of words. Internal and external spech differ in degree only : such a difference is insignificant in comparison with that betwixt the prior unconscious, or subconscious, and automatie reproduction of words and the sequent conscious and voluntary reproduction of words; the latter alone is spech, either internal or external. Whether I can show that there is this kind of duality or not, it remains certain that our patient retains a service of words, and yet ordinarily uses none in speech. The retention of that service of words which is not a speech nse of words, is sometimes spoken of as a retention of "memory of" words, or of "ideas of" words. But as there is no memory or idea of words apart from having words, actually or potentially, it is better to say that the patient retains words serving in other ways than in speech; wo should say of his speechlessness, not that he has lost the memory of words, but simply that he has lost those words which serve in spech.

When we consider more fully the duality of the Verbalising process, of which the second "half" is speech, we shall try to show that there is a duality also in the revival of the 
images aymbolised; that perception is the termination of a stage beginning by the unconsoious or subconscious revival of images which are in effect "image symbols"; that we think not only by aid of those symbols, ordinarily so-called (words), but by aid of symbol-images. It is, I think, bocause speech and perception are preceded by an unconscious or subconscious reproduction of words and images, that we seem to have "faculties" of speech and of perception, as it were, above and independent of the rest of ourselves. We seem to have a memory or ideas ${ }^{1}$ of words and words; having really the two kinds of service of words. The evidence of disease shows, it is supposed, that the highest mentation arises out of our whole organised states, out of ourselves-that Will, Memory, \&c., "come from below," and do not stand sutocratically "above," governing the mind; they are simply the now highest, or latest, state of our whole selves. In simple cases of deliriam (partial imperception with inferior perception) as when a patient takes his nurse to be his wife, we find, I think, a going dewn to and a revelation of what would have been when he was sane, the lower and earlier step towards his true recognition or perception of the nurse.

The first step towards his recognition of her when he was sane, would be the unconscious, or subconscions, and automatic reproduction of his, or of one of his, well-organised symbolimages of woman; the one most or much organised in him would be his wife. To say what a thing is is to say what it is like; he would not have known the nurse even as a woman, unless he had already an organised image of at least one woman. The popular. notion is, that by a sort of faculty of perception, he would recognise her without a prior stage in which, he being passive, an organised image was roused in him by the mere presence of the nurse; the popular notion almost seems to imply the contradiction that he first sees her, in the sense of recognising her, and then sees her as like his already acquired or organised image

1 The so-called idea of a word, in oontradistinction to the word, is itself a word Bubconsciously revived, or revivable, before the oonscious revival or revivability of the same word, which latter, in contradistinction to the so-called idea of a word, is the so-called word itself-the word. 
of some woman. We seem to ourselves to Perceive, as also to Will and to Remember, without prior stages, because these prior stages are unconscious or subconscious. It seems to me that in delirium the patient is reduced to conditions which are revelations of, or of parts of, the lower earlier and prior stages; the lower or earlier stages are then conscious. They are the then highest or latest conscious states. When the patient becomes delirious, he takes the nurse to be his wife. More or fewer of the highest nervous arrangements being then exhausted, the final stage is not possible; there is only the first stage; the reproduction of his well-organised symbolimage is all there is, and that is all the nurse can be to him; she is, to him, his wife. The symbol-image is then vividly reproduced because the centres next lower than those exhausted are in abnormally great activity (note, that there are two conditions, one negative and the other positive). There is a deepening of consciousness in the sense of going down to lower earlier and more organised states, which in health are mostly unconscious or subconscious, and precede higher or later conscious states; in other words with loss or defect of object consciousness, even in sleep with dreaming, there is increasing subject consciousness; on the physical side, increasing energising of those lower centres which are in the daytime more slightly energising during that unbroken subconscions "dreaming," from which the serial states, constituting our latest or highest object conscionsness, are the continual " awakenings."

It is supposed that the well organised images spoken ofin effect arbitrary images, symbol-images, those which become vivid and are "uppermost" in delirium, and then cerse to be mere symbols-constitute what seems to be a "general notion" or "abstract idea" of such things as "horse," "swiftness," \&c.; their particularity (that they are only images if some horse or horses, of some swift moving thing or things) not appearing, because they are unconscious or subconscious; they served once as images of particular things, and at length as symbol-images of a class of images of things, as well as images of the particular things.

At page 319 we spoke of the right half of the brain us 
being the part during the activity of which the most nearly unconscious and most automatic service of words begins, and of the left as the half during activity of which there is that sequent verbal action which is Speech. The division is too abrupt; some speech-voluntary use of words-is, as we have seen, when alluding to Occasional Utterances, possible to the man who is rendered practically speechless by disease in the left half. Again, from disense of the right half, there is not loss of that most antomatic service of words which enables us to understand speech. The thing which it is important to show is, that mentation is dual, and that physically the unit of function of the nervous system is double the unit of composition; not that one half of the brain is " automatic" and the other "voluntary."

Having now spoken of the kind of case we shall consider, and having added remarks, with the endeavour to show how the several symptoms-negative and positive-are related one to another, we shall be able to give reasons for excluding other kinds of cases of speechlessness.

We are not concerned with cases of all persons who do not speak. We shall not, for example, deal with those untrained deaf-mutes who never had speech, but with the cases of those persons only who have had it, and lost it by disease. The condition of an untrained deaf-mute is in very little comparable with that of our arbitrarily-taken case of loss of speech. The deaf-mute's brain is not diseased, but, because he is deaf, it is uneducated (or in anatomical and physiological phraseology undeveloped) so as to serve in speech. Our speechless patient is not deaf. Part of our speechless patient's brain is destroyed; he has lost nervous arrangements which had been trained in speech. Moreover, our speechless man retains a service of words which is not speech ; untrained deaf-mutes have no words at all. Further, the untrained deaf-mute has his natural system of signs, which to him is of speech value so far as it goes. $\mathrm{He}$ will think by aid of these symbols as we do by aid of words. Our speechless patient is defective even in such slight

1 We must not confound the flnger-talk with the "natural" system of aigns. They are essoutially different. No one upposes that words are escential for

VOL. I. 
pantomime as we may reasonably suppose to have been easy to him before his illness. The deaf-mute may have acquired for talking and thinking the common arbitrary system of deaf-mute signs (finger-talk), or he may have been taught by the new method to speak as we do, and thus have ceased to be mute. But when not taught to speak, he is not in a condition even roughly comparable with that of a man who has lost speech. No doubt by disease of some part of his brain the deaf-mute might lose his natural system of signs, which are of some speech value to him, but he could not lose speech, having never had it. Much more like our speechless patient's condition is that of the little child which has been taught to understand speech, and has not yet spoken.

There is another set of cases of so-called loss of speech, which we shall not consider as real loss of speech. I prefer to say that these patients do not speak : cases of some persons are meant, who do not talk and yet write perfectly. This may seem to be an arbitrary exclusion. There is in most of these cases an association of symptoms, which never arises from any local disease of any part of the nervous system; the 80-called association is a mere jumble of symptoms. Let us state the facts. The patients are nearly always boys or unmarried women. The bearing of this is obvious. The socalled loss.of spech is a total non-utterance, whereas it is an excessively rare thing for a patient who does not speak, because his brain is locally diseased, to have no utterance whatever; I do not remember seeing one such case in which there was not $\operatorname{som} \theta$ utterance (recurring utterance) a few days or a few weeks after the onset of the illness; the absolute psendospeechlessness may remain for months. They cannot be mute from paralysis of the articulatory muscle, because they swallow well. Frequently there is loss of voice also-they get out no sounds except, perhaps, grunts, \&c.-and yet they congh ringingly and breathe without hoarseness or stridor; there is no evidence of laryngeal disease. Now loss of voice never occurs with loss of speech from local disense of one side of the

thonght, but only that come symbols are essential for concoptual thought, although it may be that people with " natural" symbols do not reach that higher degree of abstract thinking which people do who have words. 
brain. No disease of the larynx would cause loss of speech or loss of articulation. The patients often "lose" their speech. after calamity or worry. In these cases there is no hemiplegia and no other one-sided condition from first to last. They often, after months of not-speaking, recover absolutely and immodiately after some treatment which can have no therapentical effect, o.g. a liniment rubbed on the back, a single faradaio stimulation of the rocal cords or of the neck. Dr. Wilks has reported a case of "cure" of a girl who had not spoken for months; she had also "lost" the use of her legs. Knowing well what was the general nature of the case, Dr. Wilks, by speaking kindly to her, and giving her an excuse for recovery in the application of faradisation, got her well in a fortnight. Sometimes the so-called speechless patient speaks inadvertently when suddenly asked a question, and then goes on talking; is well again. Sometimes speech is surprised out of her. Thus a woman, whose case is recorded by Durham, when told to cry "ah!" when the spatula was holding down her tongue, pushed his hand away, saying, "How can I, with that thing in my mouth?" She then said, "Oh! I have spoken." She was "cured." I believe that patients, "spechless" as described, might be "cured" by faradisation of the vocal cords, or by a thunderstorm, or by quack medicines or appliances, or by mesmerism, or by wearing a charm, or-not speaking flippantly. -by being " prayed over."

Sometimes these cases are spoken of as cases of "emotional aphasia"- the speochlessness - is said to be "caused by" emotional excitement, because it often comes on after emotional disturbance.

I submit that the facts that the patients do not talk and do write and do swallow are enough to show thet there is no disease at all, in any sense except that the patients are hysterical (which is saying nothing explanatory), or that they are pretending. There can be no looal diserse, at any rate.

These cases are spoken of at length, although they are excluded, because they are sometimes adduced as instances of aphasia, or loss of speech proper, with ability to write remaining. I confess that were I brought face to face with a man whom I believed to have local disease of his brain, who did not 
talk, and yet wrote well, I should conclude that he did speak intermally although he could not talk. To say that he cannot speak and yet can express himself in writing is equivalent, I think, to saying ho cannot speak and yet he can speak.

[A further instalment of this article will appear in some future number of BRATN.] 